\title{
Guided bone regeneration of peri-implant defects with particulated and block xenogenic bone substitutes
}

Benic, Goran I ; Thoma, Daniel S ; Muñoz, Fernando ; Sanz Martin, Ignacio ; Jung, Ronald E ; Hämmerle, Christoph H F

\begin{abstract}
AIM To test whether an equine bone substitute block used for guided bone regeneration (GBR) of peri-implant defects renders different results from bovine block or particulated bone substitutes regarding the dimensions of the augmented ridge and the amount of new bone. MATERIAL AND METHODS Mandibular premolars and molars were extracted in eight dogs. After 4 months, four semi-saddle bone defects were created in each mandible and one titanium implant was inserted into every site. Bone augmentation by GBR was attempted using the following randomly assigned modalities: (i) particulated deproteinized bovine bone mineral (DBBM) + a collagen membrane (CM), (ii) block DBBM + CM, (iii) equine bone substitute block + CM, and (iv) empty controls. After 4 months, one central and two lateral sections of each site were prepared. Descriptive histological and histomorphometrical assessments were performed evaluating the augmented area (AA) within the former bone defect, the area of mineralized tissue (MT), non-mineralized tissue (NMT), and residual bone substitute (BS) within AA, the horizontal thicknesses of the augmented region (HTaugm ) and of the mucosa (HTmucosa ). RESULTS At the central sections, AA measured $11.2 \pm 3.3 \mathrm{~mm}(2)$ for the equine block, $9.5 \pm 2.6 \mathrm{~mm}(2)$ for DBBM block, $7.9 \pm 4.8 \mathrm{~mm}(2)$ for particulated DBBM, and $2.4 \pm 2.1 \mathrm{~mm}(2)$ for the empty control. All GBR groups rendered significantly higher values of $A A$ in comparison with control $(\mathrm{P} \leq 0.05)$. The differences in $A A$ between GBR groups did not reach statistical significance $(\mathrm{P}>0.05)$. The equine block rendered the highest values in HTaugm , although only the differences between equine block and control as well as equine block and DBBM block were statistically significant $(\mathrm{P} \leq 0.05)$. With respect to HTmucosa, all GBR groups reached significantly higher values compared to control $(\mathrm{P} \leq 0.05)$. The equine block revealed the most pronounced signs of graft degradation. CONCLUSIONS Guided bone regeneration lead to higher ridge dimensions and thicker covering mucosa than empty controls. The equine block with CM resulted in the most favorable outcomes regarding the maintenance of ridge contour. There were no significant differences regarding amount of new bone between GBR treatments.
\end{abstract}

DOI: https://doi.org/10.1111/clr.12625

Posted at the Zurich Open Repository and Archive, University of Zurich ZORA URL: https://doi.org/10.5167/uzh-113472

Journal Article

Accepted Version

Originally published at:

Benic, Goran I; Thoma, Daniel S; Muñoz, Fernando; Sanz Martin, Ignacio; Jung, Ronald E; Hämmerle, Christoph H F (2016). Guided bone regeneration of peri-implant defects with particulated and block xenogenic bone substitutes. Clinical Oral Implants Research, 27(5):567-576.

DOI: https://doi.org/10.1111/clr.12625 


\title{
Guided bone regeneration of peri-implant defects with particulated and block xenogenic bone substitutes
}

\author{
Goran I. Benic ${ }^{1}$, Daniel S. Thoma ${ }^{1}$, \\ Fernando Munoz ${ }^{2}$, Ignacio M. Sanz ${ }^{3}$, \\ Ronald E. Jung ${ }^{1}$, Christoph H.F. Hämmerle ${ }^{1}$
}

1: Clinic of Fixed and Removable Prosthodontics and Dental Material Science, Center of Dental Medicine, University of Zurich, Switzerland

2: Faculty of Veterinary, University of Santiago de Compostela, Spain

3: Faculty of Odontology, Universidad Complutense of Madrid, Madrid, Spain

Key words: alveolar ridge augmentation, alveolar ridge defect, animal study, bone, dental implants, membrane, bone substitute, bone graft, guided bone regeneration, histology, block

Running title: Block versus particulated bone substitutes for GBR

Corresponding author:

Dr. Goran I. Benic

Clinic of Fixed and Removable Prosthodontics and Dental Material Science

Center of Dental Medicine

University of Zurich

Plattenstrasse 11

8032 Zurich, Switzerland

Tel: +416343252

E-mail: goran.benic@zzm.uzh.ch 


\section{Abstract}

Aim: To test whether an equine bone substitute block used for GBR of peri-implant defects renders different results from bovine block or particulated bone substitutes regarding the dimensions of the augmented ridge and the amount of new bone.

Material \& Methods: Mandibular premolars and molars were extracted in 8 dogs. After 4 months, four semi-saddle bone defects were created in each mandible and one titanium implant was inserted into every site. Bone augmentation by GBR was attempted using the following randomly assigned modalities: (1) particulated deproteinized bovine bone mineral $(\mathrm{DBBM})+$ a collagen membrane $(\mathrm{CM}),(2)$ block DBBM + CM, (3) equine bone substitute block + CM, and (4) empty controls. After 4 months, one central and two lateral sections of each site were prepared. Descriptive histology and histomorphometric assessments were performed evaluating the augmented area (AA) within the former bone defect, the area of mineralized tissue (MT), non-mineralized tissue (NMT), and residual bone substitute (BS) within $A A$, the horizontal thicknesses of the augmented region $\left(\mathrm{HT}_{\text {augm }}\right)$ (primary outcome parameter) and of the mucosa ( $\left.\mathrm{HT}_{\text {mucosa }}\right)$.

Results: At the central sections AA measured $11.2 \pm 3.3 \mathrm{~mm}^{2}$ for the equine block, $9.5 \pm 2.6 \mathrm{~mm}^{2}$ for DBBM block, $7.9 \pm 4.8 \mathrm{~mm}^{2}$ for particulated DBBM, and $2.4 \pm 2.1 \mathrm{~mm}^{2}$ for the empty control. All GBR groups rendered significantly higher values of $A A$ in comparison to control $(p \leq 0.05)$. The differences in AA between GBR groups did not reach statistical significance $(p>0.05)$. The equine block rendered the highest values in $\mathrm{HT}_{\text {augm }}$, although only the differences between equine block and control as well as equine block and DBBM block were statistically significant $(p \leq 0.05)$. With respect to $H T_{\text {mucosa, all } G B R \text { groups }}$ reached significantly higher values compared to control $(p \leq 0.05)$. The equine block revealed the most pronounced signs of graft degradation.

Conclusions: GBR lead to higher ridge dimensions and thicker covering mucosa than empty controls. The equine block with $\mathrm{CM}$ resulted in the most favorable outcomes regarding the maintenance of ridge contour. There were no significant differences regarding amount of new bone between GBR treatments. 


\section{Introduction}

The aim of guided bone regeneration (GBR) is to allow the placement of dental implants in prosthetically correct position and to resolve the peri-implant osseous defects. In esthetically sensitive areas GBR is also applied to increase the buccal contour of the alveolar ridge to achieve a pleasing appearance of the peri-implant soft tissues.

Currently, the application of particulated xenografts in combination with resorbable collagen membranes is the most widely used and well documented method for the augmentation of peri-implant defects (Chiapasco \& Zaniboni 2009, Jensen \& Terheyden 2009). There is a large body of clinical evidence documenting that survival rates of implants placed in conjuction with GBR, while using particulated xenografts and collagen membranes, are similar to those of implants placed into native bone (Benic, et al. 2009, Jung, et al. 2013, Zitzmann, et al. 2001, Zumstein, et al. 2012). However, particulated grafting materials in combination with collagen membranes are sub-optimal for the augmentation of noncontained bone defects due to the unfavorable mechanical properties with low resistance to pressure and thus a risk for collapse (Mellonig, et al. 1998, Schwarz, et al. 2007, Strietzel, et al. 2006, Zellin, et al. 1995). In situations requiring an increase of the ridge contour, in which the volume stability of the region to be augmented is not provided by the adjacent bone walls, contour-forming augmentations by means of blocks of autogenous bone or rigid nonresorbable membranes are considered to be the treatment of choice (Benic \& Hammerle 2014). It has, however, to be taken into account that the use of autogenous bone or nonresorbable membranes is associated with several clinical drawbacks, e.g. pronounced longterm resorption of the autogenous bone over time, a high risk of post-operative complications, and the need for removal of non-resorbable membranes (Jensen \& Terheyden 2009, Donos et al. 2008).

The use of blocks of bone substitute materials may represent an effective alternative to particulated substitutes, because they provide adequate support of the covering barrier membrane. Currently, there are only limited data reporting on the application of xenogenic and allogenic blocks in combination with collagen membranes for GBR. In a clinical study, blocks of deproteinized bovine bone mineral (DBBM) and collagen membranes were applied to 12 patients to treat horizontal bone defects before implant placement (Hammerle, et al. 2008). After 9-10 months, in 11 of 12 patients the resulting bone volume was sufficient to allow implant placement in a prosthetically optimal position. It was concluded that the procedure was effective for horizontal ridge augmentation. These results are in agreement with a preclinical trial comparing autogenous bone blocks with DBBM blocks for horizontal ridge augmentation, in which a similar increase of ridge width was measured in both groups 
(De Santis, et al. 2014, De Santis, et al. 2012). In fact, 3 months after GBR all sites treated with DBBM blocks clinically appeared suitable for implant placement.

Collagen-containing equine-derived bone block substitute was recently investigated for primary ridge augmentations. Previous preclinical studies investigating different prototypes of this material reported good clinical handling and confirmed its biocompatibility (Fontana, et al. 2008, Schwarz, et al. 2010, Simion, et al. 2009). Two preclinical trials reported invasion of the block by connective tissue resulting in little bone formation (Fontana, et al. 2008, Simion, et al. 2009). In another study with a further developed prototype of the equine-derived scaffold, pronounced bone ingrowth and graft integration were observed, as well as cell-mediated degradation of the graft material (Schwarz, et al. 2010).

In a recent in-vitro study, the volume stability of particulated and block bone substitutes in combination with collagen membranes for GBR of peri-implant defects was investigated by means of cone-beam computed tomography (CBCT) (Mir-Mari, et al. 2015). It was found that wound closure and flap suturing had induced a considerable displacement of the particulated grafting material resulting in a partial collapse of the collagen membrane. The displacement of grafting material was most pronounced in the coronal portion of the augmented site at the level of the implant shoulder. In contrast, the sites augmented with block bone substitutes exhibited less collapse of the membranes. The investigators concluded that the ability to maintain the contour of the augmented region during wound closure and flap suturing was significantly enhanced when using a block bone substitute as compared to GBR with particulated material. Based on these outcomes, an in-vivo study model was designed to assess the performance of two different xenogenic blocks, 4 months after GBR with simultaneous implant placement.

The primary aim of the present proof-of-concept study was to test whether or not equine block bone substitute used for GBR of peri-implant defects renders different results as bovine block or particulated bone substitutes with respect to the dimensions of the augmented ridge. 


\section{Materials and methods}

This article was written in accordance with the ARRIVE (Animal research: Reporting of in vivo experiments) guidelines (Kilkenny et al. 2011).

\section{Animals}

Eight male adult beagle dogs (age $20 \pm 3$ months, mean weight $16.8 \mathrm{~kg}$ ) (Isoquimen, Barcelona, Spain) were included in the present study. All animals exhibited a fully erupted permanent dentition.

The animals were subjected to surgeries and housed in the Animal Experimentation Service Facility at the Veterinary Hospital Rof Codina, Lugo, Spain. Before the initiation of the trial in October 2011, the study protocol was approved by the Ethical Committee Rof Codina Foundation. All the procedures were performed according to Spanish and European Union regulations about care and use of research animals. The dogs were monitored daily during the entire study procedure by a veterinarian accredited in laboratory animal science. The animals were housed in a group kennel with indoor and outdoor areas. The indoor area presented a controlled temperature of $20-22{ }^{\circ} \mathrm{C}$ with natural light and air renewal. During the entire study period, the dogs received soft-food diet and water ad libitum. The study started after a 3-week long adaption period for the animals.

\section{Study design and randomization}

This study was designed as a randomized controlled trial with intra-subject control for the comparison of four treatment procedures. The study was performed in two surgical phases including (1) tooth extraction and (2) implant placement with simultaneous GBR of acute-type peri-implant bone defects (four defects per animal).

The experimental sites were randomly allocated to one of the four treatment procedures according to a computer-generated randomization list. Allocation to the treatment was concealed by means of sealed envelopes until the time of the GBR procedure.

\section{Surgical procedures}

The investigators participating in the study were experienced in implant placement and bone regeneration procedures.

All surgical procedures were performed under general anesthesia of the animals. The animals were premedicated with medetomidine (20 $\mu \mathrm{g} / \mathrm{kg} / \mathrm{i} . \mathrm{m}$., Esteve, Barcelona, Spain) and morphine (0.4 mg/kg/i.m., Morfina Braun 2\%, B. Braun Medical, Barcelona, Spain). The 
anesthesia was initiated by propofol ( $2 \mathrm{mg} / \mathrm{kg} / \mathrm{i} . v$., Propovet, Abbott Laboratories, Kent, UK), and maintained by inhalation of an $\mathrm{O}_{2}$ and $2.5-4 \%$ isoflurane mixture (Isobavet, ScheringPlough, Madrid, Spain). A local anesthesia composed of lidocaine and adrenalin (Anesvet ${ }^{\circledR}$, Ovejero, León, Spain) was used to reduce peri-operative pain and bleeding. During anesthesia, the animals were monitored by a veterinarian, applying electrocardiography, capnography, pulsioxymetry and blood pressure measurements. After the surgical intervention, atipamezol (50 $\mu \mathrm{g} / \mathrm{kg} / \mathrm{i} . \mathrm{m}$., Esteve, Barcelona, Spain) was administered to revert the effects of the medetomidine.

After the surgeries, pain was controlled with morphine $(0.3 \mathrm{mg} / \mathrm{kg} / \mathrm{i} . \mathrm{m}$.) for $24 \mathrm{~h}$ and, subsequently, with meloxicam $(0.1 \mathrm{mg} / \mathrm{kg} / \mathrm{s}$.i.d/p.o., Metacam, Boehringer Ingelheim, Barcelona, Spain) for 3 days. Antibiotics (amoxicillin 22 mg/kg/ s.i.d./s.c., Amoxoil retard, Syva, Leon, Spain) were administrated for 7 days.

During the first two post-operative weeks, the oral mucosa and the teeth were disinfected three times a week by using gauzes soaked in a $0.12 \%$ chlorhexidine solution (Perio-Aid Tratamiento ${ }^{\circledR}$, Dentaid, Barcelona, Spain). Subsequently, a tooth-brush and a $0.2 \%$ chlorhexidine gel (Chlorhexidine Bioadhesive Gel, Lacer, Barcelona, Spain) were used for plaque control.

\section{Surgery 1 (tooth extraction)}

The mandibular premolars P2, P3, P4 and the molars M1 and M2 were bilaterally hemi-sectioned with fissure burs and extracted by using dental elevators and forceps. Wound closure was obtained by means of resorbable sutures (Vicry ${ }^{\circledR} 5-0$, Ethicon, Issy Les Moulineaux Cedex, France).

\section{Surgery 2 (defect preparation, implant placement and GBR)}

Preparation of defects, implant placement and GBR of peri-implant bone defects were performed 4 months after tooth extraction. Following a $25 \mathrm{~mm}$-long mid-crestal incision and a vertical releasing incision at the disto-buccal aspect of the first premolar, the mucoperiostal flaps were elevated. The edentulous portion of the ridge was flattened to obtain a bucco-oral ridge width of $8 \mathrm{~mm}$. On each side of the mandible, two standardized semi-saddle-type bone defects including removal of the buccal aspect of the alveolar ridge were prepared at a distance of $4 \mathrm{~mm}$ from each other. The defects measured $10 \mathrm{~mm}$ mesiodistally, $6 \mathrm{~mm}$ bucco-orally and $5 \mathrm{~mm}$ apico-coronally (Fig. 1). All the osteotomy procedures were performed under irrigation with sterile $0.9 \%$ saline. 
One $8 \mathrm{~mm}$-long and $4 \mathrm{~mm}$-diameter titanium implant (OsseoSpeed ${ }^{\mathrm{TM}} \mathrm{S}$, ASTRA TECH Implant System, DENTSPLY Implants, Mannheim, Germany) was inserted in each defect site obtaining primary stability (Fig. 1). The implants were placed with the central axis at $5 \mathrm{~mm}$ from the mesial and the distal walls of the defect. The apico-coronal position of the implant shoulder coincided with the level of the alveolar crest at the lingual aspect. The distance between the exposed implant surface and the buccal margin of the apical bone wall measured 3 mm (Fig. 1). Titanium closure screws (ASTRA TECH Implant System, DENTSPLY Implants, Mannheim, Germany) were placed on the implants.

The defects were randomly allocated to receive one of the following treatments (Fig. 2):

- Bovine granulate: particulated DBBM (Bio-Oss ${ }^{\circledR}$ granules $0.25-1 \mathrm{~mm}$, Geistlich Pharma AG, Wolhusen, Switzerland) + a non-cross-linked native collagen membrane (CM) (Bio-Gide ${ }^{\circledR}$, Geistlich Pharma AG)

- Bovine block: DBBM cancellous block: $10 \mathrm{~mm}$ x $10 \mathrm{~mm} \times 20 \mathrm{~mm}$ (Bio-Oss ${ }^{\circledR}$ spongiosa block, Geistlich Pharma AG) + CM

- Equine block: collagen-containing cancellous equine-derived bone block: 5 $\mathrm{mm} \times 10 \mathrm{~mm} \times 10 \mathrm{~mm}$ (Geistlich Pharma AG) + CM

- Control: empty (no biomaterials)

The bovine and the equine blocks were individually shaped and adapted to fit the defects by using cylindrical carbide drills. Prior to the application, all bone substitutes were hydrated with sterile saline solution. At the sites allocated for GBR, the defects were filled with bone substitute without surpassing the contour of the alveolar ridge. CM was applied to cover the bone substitute and overlap the walls of the defect by at least $2 \mathrm{~mm}$ (Fig. 2). No screws or pins for stabilization of blocks and membranes were used. Bleeding was allowed to form a blood clot in the control sites, where no further treatment was applied.

The periosteum of the buccal flap was relieved along its base and primary wound closure was accomplished by placing horizontal mattress and interrupted sutures made of ePTFE (Gore-Tex ${ }^{\circledR}$ sutures 5-0, W.L. Gore \& Associates Inc., Flagstaff, AZ, USA). The sutures were removed after 2 weeks.

\section{Retrieval of specimens}

Four months after implant placement and GBR, the animals were sedated with medetomidine (30 $\mu \mathrm{g} / \mathrm{kg} / \mathrm{i} . \mathrm{m}$. ., Esteve, Barcelona, Spain) and subsequently sacrificed with an overdose of sodium pentobarbital (40-60 mg/kg/i.v., Dolethal, Vetoquinol, France). The 
mandibles were dissected and the experimental specimens were retrieved with intact soft tissues.

\section{Histological preparation}

Fixation of the specimens was performed in buffered formalin at a temperature of $4^{\circ} \mathrm{C}$ for 1 week. The specimens were dehydrated using ethanol solutions of increasing concentrations and subsequently embedded in a glycol methacrylate resin (Technovit 7200 VLC, Heraus-Kulzer GmbH, Werheim, Germany) (Donath \& Breuner, 1982).

Three bucco-oral sections were prepared from each implant site: (1) a central section through the long axis of the implant, (2) a lateral section $1.5 \mathrm{~mm}$ mesially to the implant, and (3) a lateral section $1.5 \mathrm{~mm}$ distally to the implant.

Tissue blocks were cut into $200 \mu \mathrm{m}$-thick sections using a diamond band saw (Exakt Apparatebau, Norderstedt, Germany). The sections were ground and polished to a thickness of $40 \mu \mathrm{m}$ (Exakt Apparatebau, Norderstedt, Germany). All the sections were stained with toluidine blue (Schenk, et al. 1984).

\section{Histological and histomorphometrical analyses}

Histological and histomorphometrical analyses were performed by one experienced investigator masked to the specific experimental conditions. For image capturing, a light microscope (BX51, Olympus, Tokyo, Japan) connected with a digital color camera (DP71, Olympus, Tokyo, Japan) was used.

A semi-quantitative histological evaluation was performed according to the ISO 10993-6 standards. The following grading scale was used: $0=$ absent, $1=$ slight, $2=$ moderate, $3=$ marked, and $4=$ severe.

For histomorphometrical analysis, digital images were evaluated using two PC-based image analysis softwares (Cell-sens 1.5, Olympus Corporation, Japan and Microimage 4.0, Media Cybernetics, Silver Springs, MD, USA).

For each central section, the following variables were assessed:

- the augmented area (AA) $\left(\mathrm{mm}^{2}\right)$ within the former bone defect

- the area of mineralized tissue (MT) $\left(\mathrm{mm}^{2}\right)$, non-mineralized tissue (NMT) $\left(\mathrm{mm}^{2}\right)$, and residual bone substitute $(B S)\left(\mathrm{mm}^{2}\right)$ within AA 
- the horizontal thickness of the augmented region measured in a direction perpendicular to the implant axis at the level of the implant shoulder $\left(\mathrm{HT}_{\text {augm }}\right.$ omm) (primary outcome variable) and at $1 \mathrm{~mm}, 2 \mathrm{~mm}$, and $3 \mathrm{~mm}$ apical to the implant shoulder $\left(\mathrm{HT}_{\text {augm } 1 \mathrm{~mm}}-\mathrm{HT}_{\text {augm } 3 \mathrm{~mm}}\right)(\mathrm{mm})$

- the horizontal thickness of the mucosa at the level of the implant shoulder $\left(\mathrm{HT}_{\text {mucosa } 0 \mathrm{~mm}}\right)$ and at $1 \mathrm{~mm}$ apical to the implant shoulder $\left(\mathrm{HT}_{\text {mucosa } 1 \mathrm{~mm}}\right)(\mathrm{mm})$

- the horizontal thickness of the augmented region + mucosa at the level of the implant shoulder $\left(\mathrm{HT}_{\text {total }} \mathrm{Omm}\right)$ and at $1 \mathrm{~mm}$ apical to the implant shoulder $\left(\mathrm{HT}_{\text {total } 1 \mathrm{~mm}}\right)(\mathrm{mm})$

For each lateral section, the following variables were assessed:

- $\mathrm{AA}, \mathrm{MT}, \mathrm{NMT}, \mathrm{BS}$

- the surface fraction of bone substitute in contact with newly formed mineralized tissue (BS-MT surface$)(\%)$

\section{Statistical analysis}

The animal was chosen as the unit for the statistical analysis. The primary outcome parameter was $\mathrm{HT}_{\text {augm } 0 \mathrm{~mm}}$. The values for mesial and distal lateral sections were averaged to one value per implant site. The data were reported by using means, standard deviations (SD), ranges, 95\% confidence intervals $(\mathrm{Cl})$, medians, and interquartile ranges (IQR) (SPSS version 18.0, SPSS Inc., Chicago, IL, USA). The Wilcoxon's signed rank test was applied to detect differences between the treatments. The results of tests with $p$-values $\leq 0.05$ were considered statistically significant. Due to the exploratory nature of this study, no sample size calculation and no correction for multiple testing were performed. 


\section{Results}

\section{Clinical findings}

Considerable differences regarding the clinical manageability were observed between bovine and equine blocks. While bovine blocks frequently fractured during trimming and application into the bone defect, the equine blocks appeared mechanically stable, permitting effective shaping. Moreover, the slight elasticity of the equine material allowed "press-fit" adaptation and mechanical anchorage within the box-shaped defects.

A post-operative mucosal dehiscence with implant loss was observed only in one site augmented with a bovine block. A total of 8 bovine granulate, 7 bovine block, 8 equine block and 8 control sites were available for the histological and the histomorphometrical analyses.

\section{Histological findings}

The results of the semi-quantitative analysis are presented in Tables A1 and A2 (Appendix).

All the implants were osseointegrated. In the majority of the sites the most coronal bone-to-implant-contact at the lingual aspect of the implant was located coronally to the implant shoulder.

In the empty control sites re-establishment of the ridge contour was less effective as compared with all other treatment groups (Fig. 3 and 4). This resulted in the collapse of the mucosa that was particularly pronounced at the central sections. DBBM particles were disseminated in the apical and oral portions of the augmented regions. A partial displacement of granules apically to the former defect was detected in $4 / 8(50 \%)$ cases at central sections and in at 3/8 (38\%) cases at lateral sections. Bovine and equine blocks showed a similar looking interconnected trabecular system. Nonetheless, differences were found regarding the mechanical stability of block materials. Microfractures of the trabeculae of the bovine block were detected in 6/7 (86\%) cases at central sections and in 4/7 (57\%) cases at lateral sections (Fig. 5). These cracks were colonized by connective tissue cells. In one case out of seven (14\%), apical displacement of fragments of bovine block was observed at central and at lateral sections. No fractures or displacement of the grafting material were detected at the specimens treated with the equine block.

The bovine granules revealed the lowest amount of degradation signs followed by the bovine block. A small number of inflammatory cells were detected around the bovine-derived materials. Bovine blocks were surrounded by a small number of macrophages and osteoclasts. In contrast, the equine block often showed a marked biodegradation of the 
trabeculae that were surrounded by a significant amount of macrophages (Fig. 6). Moreover, the equine-derived material was frequently associated with the presence of foci of plasmatic and lymphocytic-like cells. In the cases without pronounced signs of degradation, the equine block was well kept in place and the ridge contour well preserved. In two cases, equine blocks showed advanced resorption associated with a reduced ridge width.

For all treatment groups, the amount of new bone was considerably higher at the lateral sections as compared to the central sections. In the majority of the central sections, only a minor portion of the initially exposed implant surface was in contact with new bone. Considerable differences were observed regarding the regenerative potential of the bone substitutes. Particles of bovine granulate were frequently in contact with trabeculae of woven bone and with highly vascularized dense connective tissue. In general, equine and bovine blocks revealed poor bone ingrowth that originated from open marrow spaces and periosteal region (Fig. 7). The block materials were mostly invaded with a moderately vascularized dense fibrous tissue. Two animals showed a high regenerative potential exhibiting an almost complete osseous organization of the former bone defects and a pronounced resorption of the equine block (Fig. 8).

\section{Histomorphometrical results}

\section{Central sections}

AA amounted to $11.2 \pm 3.3 \mathrm{~mm}^{2}$ (SD) for the equine block, $9.5 \pm 2.6 \mathrm{~mm}^{2}$ (SD) for the bovine block, $7.9 \pm 4.8 \mathrm{~mm}^{2}$ (SD) for the bovine granulate, and $2.4 \pm 2.1 \mathrm{~mm}^{2}(\mathrm{SD})$ for the empty control (Tables 1a, 1b). All GBR groups rendered significantly higher values of AA in comparison to empty controls (equine block: $p=0.016$; bovine block: $p=0.016$; bovine granulate: $p=0.039$ ). The differences in AA between the GBR groups did not reach statistical significance $(p>0.05)$.

There were no statistically significant differences in MT and BS between the treatment groups $(p>0.05)$ (Tables 1a, 1b).

With regards to the horizontal thickness of the augmented region, $\mathrm{HT}_{\text {augm } 0 \mathrm{~mm}}-\mathrm{HT}_{\text {augm } 3 \mathrm{~mm}}$ reached the highest mean values for the equine block (Tables 1a, 1b). The differences in $\mathrm{HT}_{\text {augm }}$ between the equine block and the control were statistically significant $\left(\mathrm{HT}_{\text {augm } 0 \mathrm{~mm}}: \mathrm{p}=\right.$ $0.016, \mathrm{HT}_{\text {augm 1mm }}: \mathrm{p}=0.016, \mathrm{HT}_{\text {augm 2mm }}: \mathrm{p}=0.008$ ). In terms of horizontal thickness of the

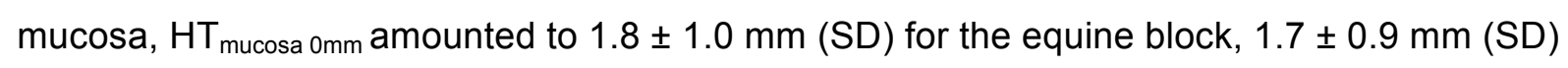
for the bovine block, $1.6 \pm 0.8 \mathrm{~mm}$ for the bovine granulate, and $0.9 \pm 0.6 \mathrm{~mm}$ for the control. All GBR groups reached significantly higher values of $\mathrm{HT}_{\text {mucosa } 0 \mathrm{~mm}}$ compared to control 
(equine block: $p=0.047$; bovine block: $p=0.047$; bovine granulate: $p=0.016)($ Tables $1 a$, 1b).

When assessing the total horizontal thickness of the augmented region + mucosa, $\mathrm{HT}_{\text {total } 0 \mathrm{~mm}}$ and $\mathrm{HT}_{\text {total } 1 \mathrm{~mm}}$ reached the highest mean values for the equine block followed by the bovine block, the bovine granulate and the control (Tables 1a, 1b). All GBR groups revealed significantly higher values of $\mathrm{HT}_{\text {total } 0 \mathrm{~mm}}$ in comparison to the empty control $(\mathrm{p}=$ 0.016). The values of $\mathrm{HT}_{\text {total } 1 \mathrm{~mm}}$ were significantly higher for equine and bovine blocks as compared to the control (equine block: $p=0.031$; bovine block: $p=0.016$ ).

\section{Lateral sections}

AA measured $19.9 \pm 5.3 \mathrm{~mm}^{2}(\mathrm{SD})$ for the equine block, $19.5 \pm 3.0 \mathrm{~mm}^{2}$ (SD) for the bovine block, $17.8 \pm 5.6 \mathrm{~mm}^{2}(\mathrm{SD})$ for the bovine granulate and $11.9 \pm 2.3 \mathrm{~mm}^{2}$ (SD) for the control (Tables $2 a, 2 b$ ). Equine and bovine blocks rendered statistically higher values of $A A$ as compared to the control (equine block: $p=0.023$; bovine block: $p=0.016$ ). The difference in AA between the bovine granulate and the control did not reach statistical significance $(p=$ $0.078)$.

MT amounted to $6.0 \pm 5.5 \mathrm{~mm}^{2}(\mathrm{SD})$ for the equine block, $4.3 \pm 3.8 \mathrm{~mm}^{2}$ (SD) for the bovine block, $5.4 \pm 2.8 \mathrm{~mm}^{2}(\mathrm{SD})$ for the bovine granulate and $8.9 \pm 2.5 \mathrm{~mm}^{2}(\mathrm{SD})$ for the control (Tables $2 a, 2 b$ ). The values of MT for the bovine block and the bovine granulate were significantly lower in comparison to the empty control $(p=0.016)$.

BS measured $2.1 \pm 1.6 \mathrm{~mm}^{2}(\mathrm{SD})$ in the equine block group, $3.5 \pm 1.1 \mathrm{~mm}^{2}(\mathrm{SD})$ in the bovine block group and $3.7 \pm 1.5 \mathrm{~mm}^{2}(\mathrm{SD})$ in the bovine granulate group (Tables 2a, $2 b)$. The differences between the equine block and the bovine materials reached statistical significance (equine block vs. bovine block: $p=0.016$; equine block vs. bovine granulate: $p=$ 0.039).

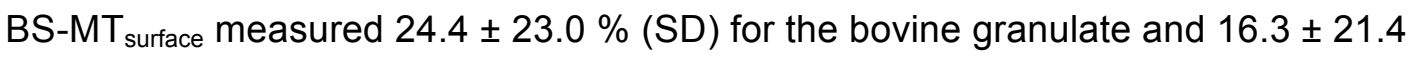
$\%$ (SD) for the bovine block (Tables $2 a, 2 b$ ). The difference between the two groups was statistically significant $(p=0.016)$. For the equine block, the corresponding value was $18.9 \pm$ $31.6 \%(S D)$. 


\section{Discussion}

The present study demonstrated a significant benefit of performing GBR over empty defects to restore deficient bone contour at peri-implant defects. When comparing the GBR groups, the equine bone block substitute in combination with $\mathrm{CM}$ reached the highest mean values in ridge dimensions, followed by DBBM block and DBBM granulate in combination with CM. The width of the augmented region at the level of the implant shoulder reached in average $0.8 \mathrm{~mm}$ for DBBM granulate and $1.8 \mathrm{~mm}$ for the equine block. However, the differences in ridge dimensions between the GBR groups did generally not reach statistical significance.

The differences in the augmented ridge dimension between the GBR groups can be explained by different mechanical properties of the grafting materials. Intra-operatively, the equine block was not prone to fractures, thereby permitting "press-fit" adaptation and mechanical anchorage within the box-shaped defects. Moreover, no fractures or displacements of this material were observed in the histological samples. In contrast, fractures of DBBM block and displacements of DBBM granules in the apical direction were often observed. The reason of this outcome was probably due to the forces applied on the alveolar ridge by dogs, which could not be controlled beyond feeding with soft diet.

The volume stability of different materials for GBR during blinded suturing of mucosal flaps was investigated in a recent in-vitro examination (Mir-Mari, et al. 2015). In this study, the stability of the following material combinations were tested by means of CBCT: (1) particulated DBBM + CM, (2) particulated DBBM + CM + fixation pins, and (3) DBBM block $+\mathrm{CM}$. The investigators found that wound closure always induced a displacement of the bone substitute, resulting in a partial collapse of $\mathrm{CM}$ in the coronal portion of the augmented site. First, the initial stability of the bone substitute and CM was enhanced by application of fixation pins. Secondly, the block bone substitute in combination with CM performed significantly better than the particulated material covered with $\mathrm{CM}$.

The stability of horizontally augmented ridge during healing was investigated in a previous animal study (Thoma, et al. 2012). The standardized acute defects were augmented with particulated DBBM, alone or in combination with a membrane. For control purposes, one defect at each animal remained untreated. The histological assessment was performed at baseline immediately after surgery, at 4 weeks and at 16 weeks postoperatively. It was found that sites augmented with bone substitutes performed significantly better compared to the empty control with respect to the ridge contour. In the majority of the augmented sites, a continuous reduction in the dimension of the augmented ridge was found between the three time-points, with the most pronounced reduction between baseline and 4 weeks. Owing to the low biodegradation rate of DBBM, a considerable resorption of the bone 
substitute during this relatively short period should be excluded. The dimensional reduction of the augmented ridges could, therefore, rather be explained by the displacement of DBBM particles during the healing period. In the same study, it was observed that the application of polyethylene glycol membrane over DBBM granules considerably decreased the amount of post-operative ridge reduction compared to the group with DBBM granules alone (Thoma, et al. 2012). This finding can be explained by the mechanical containment of the grafting material by the membrane. However, the results of this study cannot be directly compared with the data of the present trial due to different types of membrane used for GBR. A comparison of particulated and block DBBM for horizontal augmentation of chronic-type bone defects was performed in another preclinical study (Schwarz, et al. 2008). In this trial the bone substitute and CM were used alone or with an addition of growth factors. After 3 and 8 weeks, samples were prepared for histological analysis. When assessing the width of the augmented ridge, block of DBBM stabilized by titanium screws appeared to perform better in comparison to particulated DBBM. The results of these studies are in accordance with the findings of the present investigation.

With respect to the amount of new bone within the augmented area there were no significant differences between the bone substitutes. As far as the surface fraction of bone substitute in contact with new bone, bovine granulate reached higher values compared to the block materials. The difference between DBBM granulate and DBBM block reached statistical significance, indicating a superior osteoconductivity of particulated material in comparison to the block. The difference in the rate of bone ingrowth is presumably due to the differences in the macrostructure, with particulated material possibly permitting ingrowth of blood vessels and new bone. In general, bone ingrowth within the equine and the bovine blocks was limited to the peripheral areas in contact with cancellous bone. The block materials were mostly invaded by moderately vascularized fibrous tissue.

The equine block showed the most pronounced signs of biodegradation. Nevertheless, in the majority of specimens the equine block was kept in place and the ridge contour was well preserved. In the central sections, the sites treated with equine and bovine blocks presented similar amount of remaining bone substitute. In the lateral sections, the same parameter reached significantly lower values for equine block as compared to DBBM block and DBBM granulate. Macrophages, plasmatic- and lymphocytic-like cells were generally identified surrounding trabeculae of the equine block. The presence of a larger number of inflammmatory cells demonstrates the higher antigenic capacity of the collagencontaining equine block compared to DBBM. It is worth mentioning that two dogs presented a considerably higher regenerative potential in comparison with the remaining animals. The corresponding specimens revealed an almost complete degradation of the equine block and substitution by new bone. 
In an earlier study, the equine block and the DBBM block were used for horizontal ridge augmentation of acute bone defects in combination with stabilization screws and CM (Schwarz, et al. 2010). After 12 weeks, the trabecular architecture of the equine block appeared to be considerably looser when compared with the DBBM specimens. A histopathological difference between the materials was observed with respect to the presence of osteoclasts and multinucleated giant cells, which appeared to be moderately increased in the equine block group and directly involved in the degradation of this material. These findings are in agreement with the results of the semi-quantitative analysis in the present study. The observations from this study were corroborated by the histomorphometrical analysis, which revealed significantly less remaining bone substitute for the equine block compared to DBBM block (Schwarz, et al. 2010). Simultaneously, the equine block featured an increased extent of bone ingrowth compared to the bovine block. The difference between the remaining amounts of bovine and equine block was much more pronounced than the difference found in the present trial. In fact, in the previous study the amount of the remaining equine block after 3 months appeared to be lower compared to the amount of the remaining equine block after 4 months in the present trial. The lower degradation rate of the equine block tested in the present study can partially explain the increased ability to maintain the contour of the augmented ridge. An earlier preclinical trial used prototype of the equine block alone or in combination with $\mathrm{CM}$ for vertical ridge augmentation (Simion, et al. 2009). In this study, only an initial resorption of the grafting material with invasion of connective tissue and limited bone formation were observed after 5 months.

Poor osteoconductive propriety and almost no degradation of the DBBM block observed in the present study are in agreement with the findings of several previous studies (Araujo, et al. 2002, De Santis, et al. 2014, De Santis, et al. 2012, Schmitt, et al. 2013, Schwarz, et al. 2010). In these trials using DBBM blocks for onlay grafting alone or in combination with membranes, very little newly formed bone was encountered within the grafts, which were mainly invaded by connective tissue. Whether DBBM is bioresorbable still remains controversial (Berglundh \& Lindhe 1997, Fugazzotto 2003, Mordenfeld, et al. 2010). The presence of cells with osteoclastic characteristics was interpreted as a sign of ongoing resorption of DBBM (Piattelli, et al. 1999). A recent clinical trial including 20 patients found DBBM particles unchanged and integrated in the bone 11 years after sinus floor augmentation (Mordenfeld, et al. 2010).

A model of an acute-type semi-saddle defect was used to compare the performance of different bone substitutes for GBR of peri-implant bone defects. This type of defect has been applied in several previous studies for the investigation of GBR with or without simultaneous placement of implants (Jung, et al. 2011, Schwarz, et al. 2010, Thoma, et al. 
2012). Other studies used a chronic-type bone defect, which is considered to simulate better the clinical reality (Schwarz, et al. 2008). However, this type of defect was reported to vary in size at the time-point of the GBR surgery (von Arx, et al. 2001). The chronification of the defects was, therefore, omitted to standardize the initial defect dimension in all groups, aiming at reproducible surgical procedure and histomorphometrical analysis. Acute bone defects have a higher potential for regeneration as a biologic reaction to the surgical trauma (Schenk 1992). Nevertheless, the experimental model used in the present study can be considered challenging for bone regeneration, which is demonstrated by the poor spontaneous regeneration in the empty control. This finding may be explained by the large defect size and the fact that the implant shielded the cancellous bone in the central region of the defect. Consequently, for all treatment groups the amount of mineralized tissue was lower at the central sections in comparison to the lateral ones. Possibly, a longer healing time would have been needed to allow more bone ingrowth into the central region of the defect. The contour of the augmented ridge was better maintained at the lateral sections in comparison to the central ones. This can be explained by the proximity of the lateral bone walls, which partially supported the barrier membrane. In other words, despite the three-wall morphology the volume of the large bone defect was not well contained by the adjacent bone walls. Therefore, the lateral sections should be considered as more adequate for the evaluation of biodegradation and osteoconductivity, whereas the volume stability of biomaterials should rather be assessed at the central sections. Moreover, information regarding dynamics of biological processes (e.g. graft degradation) might be extrapolated from the comparison between the lateral and the central sections, as these samples potentially represent different stages of the healing process.

One of the main clinical aims of bone augmentation procedures is to generate a sufficient volume of hard tissue to support the mucosa and optimize the appearance of periimplant soft tissue. The fact that the equine bone block substitute in combination with $\mathrm{CM}$ performed well regarding the maintenance of the augmented ridge contour is a clinically relevant aspect. The use of bone block substitutes for bone augmentation has the potential to enhance the performance of GBR with respect to maintenance of the augmented ridge contour and to reduce the need of non-resorbable membranes.

The small sample size and the statistical analysis without the correction for multiple testing are limitations, which have to be taken into account when interpreting the findings of the present study. Nevertheless, this proof-of-concept trial provides valuable information on the volume stability and the tissue integration of particulated and block bone substitutes for GBR. Further investigations in humans are needed to examine the clinical implications of the findings of the present study. Future clinical research should assess and monitor the long- 
term stability of the augmented ridge. The influence of augmentation procedures on implant survival and success rate needs to be determined. 


\section{Conclusion}

Within the limitations of the present study, it can be concluded that for augmentation of peri-implant bone defects:

- The application of bone substitutes and collagen membranes performed significantly better compared to empty controls with respect to the volume of the augmented ridge and the thickness of the overlying mucosa.

- The equine block resulted in the most favorable outcomes regarding the width of the augmented ridge

- In terms of new bone formation, there were no differences between the bone substitutes. In the lateral regions of the defect, the empty controls resulted in the most favorable outcomes regarding the amount of new bone.

- The equine block revealed more pronounced signs of degradation compared to the bovine-derived materials. 


\section{Acknowledgements}

The investigators gratefully acknowledge Gisela Müller (Clinic of Fixed and Removable Prosthodontics and Dental Material Science, Center of Dental Medicine, University of Zurich, Switzerland) and Dr. Ela Bingel-Erlenemeyer (Geistlich Pharma AG, Wolhusen, Switzerland) for assistance in preparing the manuscript, and Dr. Michael Mayer (Consult AG, Bern Switzerland) for assistance in analyzing the data. This study was supported by the Clinic of Fixed and Removable Prosthodontics and Dental Material Science, Center of Dental Medicine, University of Zurich, Switzerland and by a research grant from Geistlich Pharma AG, Wolhusen, Switzerland. 


\section{Table legend}

Table 1a. Results of the histomorphometrical analysis of the central sections

Table 1b. Results of the statistical test for comparisons between groups at the central sections

Table 2a. Results of the histomorphometrical analysis of the lateral sections

Table 2b. Results of the statistical test for comparisons between groups at the lateral sections 


\section{Figure legend}

Figure 1. (a) Buccal and (b) occlusal views of the bone defects prior to GBR

Figure 2. (a, b) Empty control (left) and GBR with equine-derived bone block in combination with a collagen membrane (right). (c, d) GBR procedures with particulated (left) and block (right) DBBM in combination with a collagen membrane.

Figure 3. Histological views at the central sections (original magnification $\times 10$ ): (a) equine bone block with collagen membrane (CM), (b) DBBM block with CM, (c) particulated DBBM with CM, and (d) empty control.

Figure 4. Histological views at the lateral sections (original magnification $\times 10$ ): (a) equine bone block with collagen membrane (CM), (b) DBBM block with $\mathrm{CM}$, (c) particulated DBBM with CM, and (d) empty control.

Figure 5. Microfractures of the trabeculae of bovine block (original magnification $\mathrm{x}$ 100).

Figure 6. Biodegradation of the equine block scaffold that is surrounded by a significant amount of macrophages (original magnification $\times 200$ ).

Figure 7 . The ingrowth of bone in the equine block mainly originated from open marrow spaces (original magnification $\mathrm{x} 10$ ).

Figure 8. Advanced osseous integration and pronounced resorption of an equine block specimen (original magnification $\times 10$ ). 


\section{Appendix}

Table A1. Results of the semi-quantitative histological analysis of the central sections

Table A2. Results of the semi-quantitative histological analysis of the lateral sections 


\section{References}

Araujo, M. G., Sonohara, M., Hayacibara, R., Cardaropoli, G. \& Lindhe, J. (2002) Lateral ridge augmentation by the use of grafts comprised of autologous bone or a biomaterial. An experiment in the dog. Journal of Clinical Periodontology 29: 1122-1131.

Benic, G. I. \& Hammerle, C. H. (2014) Horizontal bone augmentation by means of guided bone regeneration. Periodontology 2000 66: 13-40.

Benic, G. I., Jung, R. E., Siegenthaler, D. W. \& Hammerle, C. H. (2009) Clinical and radiographic comparison of implants in regenerated or native bone: 5-year results. Clinical Oral Implants Research 20: 507-513.

Berglundh, T. \& Lindhe, J. (1997) Healing around implants placed in bone defects treated with bio-oss. An experimental study in the dog. Clinical Oral Implants Research 8: 117-124.

Chiapasco, M. \& Zaniboni, M. (2009) Clinical outcomes of gbr procedures to correct periimplant dehiscences and fenestrations: A systematic review. Clinical Oral Implants Research 20 Suppl 4: 113-123.

De Santis, E., Lang, N. P., Favero, G., Beolchini, M., Morelli, F. \& Botticelli, D. (2014) Healing at mandibular block-grafted sites. An experimental study in dogs. Clinical Oral Implants Research.

De Santis, E., Lang, N. P., Scala, A., Vigano, P., Salata, L. A. \& Botticelli, D. (2012) Healing outcomes at implants installed in grafted sites: An experimental study in dogs. Clinical Oral Implants Research 23: 340-350.

Donos, N., Mardas, N. \& Chadha, V. (2008) Clinical outcomes of implants following lateral bone augmentation: systematic assessment of available options (barrier membranes, bone grafts, split osteotomy). Journal of Clinical Periodontology 35 Suppl 8: 173-202

Fontana, F., Rocchietta, I., Dellavia, C., Nevins, M. \& Simion, M. (2008) Biocompatibility and manageability of a new fixable bone graft for the treatment of localized bone defects: Preliminary study in a dog model. International Journal of Periodontics and Restorative Dentistry 28: 601-607.

Fugazzotto, P. A. (2003) Gbr using bovine bone matrix and resorbable and nonresorbable membranes. Part 1: Histologic results. International Journal of Periodontics and Restorative Dentistry 23: 361-369.

Hammerle, C. H., Jung, R. E., Yaman, D. \& Lang, N. P. (2008) Ridge augmentation by applying bioresorbable membranes and deproteinized bovine bone mineral: A report of twelve consecutive cases. Clinical Oral Implants Research 19: 19-25.

Jensen, S. S. \& Terheyden, H. (2009) Bone augmentation procedures in localized defects in the alveolar ridge: Clinical results with different bone grafts and bone-substitute materials. International Journal of Oral and Maxillofacial Implants 24 Suppl: 218-236.

Jung, R. E., Fenner, N., Hammerle, C. H. \& Zitzmann, N. U. (2013) Long-term outcome of implants placed with guided bone regeneration (gbr) using resorbable and non-resorbable membranes after 12-14 years. Clinical Oral Implants Research 24: 1065-1073. 
Jung, R. E., Kokovic, V., Jurisic, M., Yaman, D., Subramani, K. \& Weber, F. E. (2011) Guided bone regeneration with a synthetic biodegradable membrane: A comparative study in dogs. Clinical Oral Implants Research 22: 802-807.

Kilkenny, C., Browne, W. J., Cuthill, I. C., Emerson, M. \& Altman, D. G. (2010) Improving bioscience research reporting: the ARRIVE guidelines for reporting animal research. Public Library of Science Biology 8, e1000412 doi:10.1371/journal.pbio.1000412.

Mellonig, J. T., Nevins, M. \& Sanchez, R. (1998) Evaluation of a bioabsorbable physical barrier for guided bone regeneration. Part i. Material alone. International Journal of Periodontics and Restorative Dentistry 18: 139-149.

Mir-Mari, J., Wui, H., Jung, R. E., Hämmerle, C. \& Benic, G. I. (2015) Influence of blinded wound closure on the volume stability of different GBR materials: an in vitro cone-beam computed tomographic examination. Clinical Oral Implants Research Epub ahead of print.

Mordenfeld, A., Hallman, M., Johansson, C. B. \& Albrektsson, T. (2010) Histological and histomorphometrical analyses of biopsies harvested 11 years after maxillary sinus floor augmentation with deproteinized bovine and autogenous bone. Clinical Oral Implants Research 21: 961-970.

Piattelli, M., Favero, G. A., Scarano, A., Orsini, G. \& Piattelli, A. (1999) Bone reactions to anorganic bovine bone (bio-oss) used in sinus augmentation procedures: A histologic longterm report of 20 cases in humans. International Journal of Oral and Maxillofacial Implants 14: $835-840$.

Schenk, R. K. (1992) Biology of fracture repair In: Browner, B. D., Jupiter, J.B., Levine, A.M. \& Traften, P.G., ed. Skeletal trauma, 31-75: Philadelphia: Saunders.

Schenk, R. K., Olah, A. J. \& Herrmann, W. (1984) Preparation of calcified tissues for light microscopy In: Dickson, G. R., ed. Methods of calcified tissue preparations, 1-56.

Amsterdam: Elsevier.

Schmitt, C., Lutz, R., Doering, H., Lell, M., Ratky, J. \& Schlegel, K. A. (2013) Bio-oss(r) blocks combined with bmp-2 and vegf for the regeneration of bony defects and vertical augmentation. Clinical Oral Implants Research 24: 450-460.

Schwarz, F., Ferrari, D., Balic, E., Buser, D., Becker, J. \& Sager, M. (2010) Lateral ridge augmentation using equine- and bovine-derived cancellous bone blocks: A feasibility study in dogs. Clinical Oral Implants Research 21: 904-912.

Schwarz, F., Herten, M., Ferrari, D., Wieland, M., Schmitz, L., Engelhardt, E. \& Becker, J. (2007) Guided bone regeneration at dehiscence-type defects using biphasic hydroxyapatite + beta tricalcium phosphate (bone ceramic) or a collagen-coated natural bone mineral (biooss collagen): An immunohistochemical study in dogs. International Journal of Oral and Maxillofacial Surgery 36: 1198-1206.

Schwarz, F., Rothamel, D., Herten, M., Ferrari, D., Sager, M. \& Becker, J. (2008) Lateral ridge augmentation using particulated or block bone substitutes biocoated with rhgdf-5 and rhbmp-2: An immunohistochemical study in dogs. Clinical Oral Implants Research 19: 642652.

Simion, M., Nevins, M., Rocchietta, I., Fontana, F., Maschera, E., Schupbach, P. \& Kim, D. M. (2009) Vertical ridge augmentation using an equine block infused with recombinant human platelet-derived growth factor-bb: A histologic study in a canine model. International Journal of Periodontics and Restorative Dentistry 29: 245-255. 
Strietzel, F. P., Khongkhunthian, P., Khattiya, R., Patchanee, P. \& Reichart, P. A. (2006) Healing pattern of bone defects covered by different membrane types--a histologic study in the porcine mandible. J Biomed Mater Res B Appl Biomater 78: 35-46.

Thoma, D. S., Dard, M. M., Halg, G. A., Ramel, C. F., Hammerle, C. H. \& Jung, R. E. (2012) Evaluation of a biodegradable synthetic hydrogel used as a guided bone regeneration membrane: An experimental study in dogs. Clinical Oral Implants Research 23: 160-168.

von Arx, T., Cochran, D.L., Hermann, J.S., Schenk, R.K., Higginbottom, F.L. \& Buser, D. (2001) Lateral ridge augmentation and implant placement: an experimental study evaluating implant osseointegration in different augmentation materials in the canine mandible. The International Journal of Oral \& Maxillofacial Implants 16: 343-354.

Zellin, G., Gritli-Linde, A. \& Linde, A. (1995) Healing of mandibular defects with different biodegradable and non-biodegradable membranes: An experimental study in rats.

Biomaterials 16: 601-609.

Zitzmann, N. U., Scharer, P. \& Marinello, C. P. (2001) Long-term results of implants treated with guided bone regeneration: A 5-year prospective study. International Journal of Oral and Maxillofacial Implants 16: 355-366.

Zumstein, T., Billstrom, C. \& Sennerby, L. (2012) A 4- to 5-year retrospective clinical and radiographic study of neoss implants placed with or without gbr procedures. Clinical Implant Dentistry and Related Research 14: 480-490. 


\begin{tabular}{|c|c|c|c|c|c|}
\hline \multirow[t]{2}{*}{ Parametar } & \multirow[t]{2}{*}{ Unit } & \multicolumn{4}{|l|}{ Treatment modality } \\
\hline & & $\begin{array}{l}\text { Equine block (EB) } \\
(n=8)\end{array}$ & $\begin{array}{l}\text { Bovine block (BB) } \\
(n=7)\end{array}$ & $\begin{array}{l}\text { Bovine granules (BG) } \\
(n=8)\end{array}$ & $\begin{array}{l}\text { Empty control (C) } \\
(n=8)\end{array}$ \\
\hline & & \multicolumn{4}{|l|}{$\begin{array}{l}\text { Mean } \pm \text { SD } \\
(\mathrm{Q} 1, \text { median, Q3) }\end{array}$} \\
\hline AA & $\mathrm{mm} 2$ & $\begin{array}{l}11.2 \pm 3.3 \\
(8.8,11.5,13.9)\end{array}$ & $\begin{array}{l}9.5 \pm 2.6 \\
(8.1,9.6,11.6)\end{array}$ & $\begin{array}{l}7.9 \pm 4.8 \\
(3.8,8.8,11.0)\end{array}$ & $\begin{array}{l}2.4 \pm 2.1 \\
(1.2,1.9,2.5)\end{array}$ \\
\hline MT & $\mathrm{mm} 2$ & $\begin{array}{l}1.8 \pm 2.6 \\
(0.3,0.4,2.2)\end{array}$ & $\begin{array}{l}1.2 \pm 1.6 \\
(0.2,0.3,2.0)\end{array}$ & $\begin{array}{l}2.2 \pm 1.5 \\
(1.0,2.3,2.9)\end{array}$ & $\begin{array}{l}1.9 \pm 1.8 \\
(0.9,1.5,1.9)\end{array}$ \\
\hline NMT & $\mathrm{mm} 2$ & $\begin{array}{l}7.6 \pm 4.1 \\
(6.0,8.8,10.7)\end{array}$ & $\begin{array}{l}6.6 \pm 2.7 \\
(6.2,6.6,8.2)\end{array}$ & $\begin{array}{l}4.6 \pm 3.4 \\
(2.3,4.5,6.9)\end{array}$ & $\begin{array}{l}0.4 \pm 0.3 \\
(0.3,0.4,0.5)\end{array}$ \\
\hline BS & $\mathrm{mm} 2$ & $\begin{array}{l}1.8 \pm 1.2 \\
(0.8,2.3,2.7)\end{array}$ & $\begin{array}{l}1.7 \pm 0.8 \\
(1.4,1.9,2.2)\end{array}$ & $\begin{array}{l}1.1 \pm 0.8 \\
(0.6,1.1,1.6)\end{array}$ & - \\
\hline $\mathrm{HT}_{\text {augm } 0 \mathrm{~mm}}$ & $\mathrm{~mm}$ & $\begin{array}{l}1.7 \pm 1.1 \\
(0.9,1.7,2.6)\end{array}$ & $\begin{array}{l}0.6 \pm 1.0 \\
(0.0,0.0,0.9)\end{array}$ & $\begin{array}{l}0.8 \pm 1.1 \\
(0.0,0.0,1.7)\end{array}$ & $\begin{array}{l}0 \pm 0 \\
(0.0,0.0,0.0)\end{array}$ \\
\hline $\mathrm{HT}_{\text {augm } 1 \mathrm{~mm}}$ & $\mathrm{~mm}$ & $\begin{array}{l}2.2 \pm 1.1 \\
(1.8,2.6,3.1)\end{array}$ & $\begin{array}{l}1.6 \pm 0.9 \\
(1.4,1.6,2.0)\end{array}$ & $\begin{array}{l}1.4 \pm 1.4 \\
(0.0,1.5,2.3)\end{array}$ & $\begin{array}{l}0 \pm 0 \\
(0.0,0.0,0.0)\end{array}$ \\
\hline $\mathrm{HT}_{\text {augm } 2 \mathrm{~mm}}$ & $\mathrm{~mm}$ & $\begin{array}{l}2.6 \pm 1.0 \\
(2.1,2.9,3.3)\end{array}$ & $\begin{array}{l}2.2 \pm 1.1 \\
(1.9,2.6,2.8)\end{array}$ & $\begin{array}{l}1.9 \pm 1.6 \\
(0.7,2.1,2.8)\end{array}$ & $\begin{array}{l}0.1 \pm 0.2 \\
(0.0,0.0,0.0)\end{array}$ \\
\hline $\mathrm{HT}_{\text {augm } 3 \mathrm{~mm}}$ & $\mathrm{~mm}$ & $\begin{array}{l}2.8 \pm 0.8 \\
(2.6,3.0,3.2)\end{array}$ & $\begin{array}{l}2.5 \pm 0.6 \\
(2.2,2.6,2.9)\end{array}$ & $\begin{array}{l}2.2 \pm 1.8 \\
(1.1,2.3,3.1)\end{array}$ & $\begin{array}{l}0.5 \pm 0.7 \\
(0.0,0.0,1.0)\end{array}$ \\
\hline $\mathrm{HT}_{\text {mucosa 0mm }}$ & $\mathrm{mm}$ & $\begin{array}{l}1.8 \pm 1.0 \\
(1.0,1.7,2.2)\end{array}$ & $\begin{array}{l}1.7 \pm 0.9 \\
(1.2,1.4,2.3)\end{array}$ & $\begin{array}{l}1.6 \pm 0.8 \\
(1.0,1.7,2.1)\end{array}$ & $\begin{array}{l}0.9 \pm 0.6 \\
(0.4,0.8,1.2)\end{array}$ \\
\hline $\mathrm{HT}_{\text {mucosa } 1 \mathrm{~mm}}$ & $\mathrm{~mm}$ & $\begin{array}{l}1.3 \pm 0.6 \\
(1.0,1.3,1.8)\end{array}$ & $\begin{array}{l}1.6 \pm 0.5 \\
(1.3,1.8,1.9)\end{array}$ & $\begin{array}{l}1.4 \pm 0.3 \\
(1.3,1.5,1.6)\end{array}$ & $\begin{array}{l}1.3 \pm 0.5 \\
(0.9,1.1,1.7)\end{array}$ \\
\hline $\mathrm{HT}_{\text {total } 0 \mathrm{~mm}}$ & $\mathrm{~mm}$ & $\begin{array}{l}3.3 \pm 1.2 \\
(2.3,3.4,4.2)\end{array}$ & $\begin{array}{l}2.3 \pm 0.9 \\
(1.8,2.6,3.0)\end{array}$ & $\begin{array}{l}2.5 \pm 1.4 \\
(1.7,2.6,3.3)\end{array}$ & $\begin{array}{l}0.9 \pm 0.6 \\
(0.4,0.8,1.2)\end{array}$ \\
\hline $\mathrm{HT}_{\text {total } 1 \mathrm{~mm}}$ & $\mathrm{~mm}$ & $\begin{array}{l}3.3 \pm 1.0 \\
(2.7,3.6,3.9)\end{array}$ & $\begin{array}{l}3.2 \pm 0.8 \\
(2.8,3.4,3.6)\end{array}$ & $\begin{array}{l}2.8 \pm 1.4 \\
(1.8,2.9,3.3)\end{array}$ & $\begin{array}{l}1.3 \pm 0.5 \\
(0.9,1.1,1.6)\end{array}$ \\
\hline $\begin{array}{l}\text { AA, augmen } \\
\text { horizontal th } \\
\text { thickness of } \\
\text { augmented } \\
\text { quartile; Q3 }\end{array}$ & $\begin{array}{l}\text { ted are } \\
\text { ickness } \\
\text { the mu } \\
\text { region - } \\
\text { third g }\end{array}$ & $\begin{array}{l}\text { mineralized tissue; } \\
\text { augmented region } \\
\text { easured } \mathrm{x} \mathrm{mm} \text { apica } \\
\text { sa measured } \mathrm{x} \mathrm{mm}\end{array}$ & $\begin{array}{l}\mathrm{T} \text {, non-mineralized } \\
\text { asured } \mathrm{x} \text { mm apica } \\
\text { the implant shoul } \\
\text { cal to the implant } \mathrm{s}\end{array}$ & $\begin{array}{l}\text { ue; BS, bone substitut } \\
\text { the implant shoulder; } \\
\mathrm{HT}_{\text {total xmm }} \text {, horizontal } \\
\text { Ider; SD, standard dev }\end{array}$ & $\begin{array}{l}\mathrm{e}, \mathrm{HT}_{\text {augm xmm }} \\
\mathrm{HT}_{\text {mucosa xmm }} \text {, horizontal } \\
\text { thickness of the } \\
\text { iation; } \mathrm{Q} 1 \text {, first }\end{array}$ \\
\hline
\end{tabular}




\begin{tabular}{|c|c|c|c|c|c|c|}
\hline \multirow[t]{2}{*}{ Parametar } & \multicolumn{6}{|c|}{ Statistical analysis* } \\
\hline & EB vs BB & EB vs BG & EB vs C & BB vs BG & BB vs C & BG vs C \\
\hline$\overline{A A}$ & 0.297 & 0.148 & $0.016^{\dagger}$ & 0.578 & $0.016+$ & $0.039+$ \\
\hline MT & 0.219 & 0.461 & 0.383 & 0.109 & 0.078 & 0.742 \\
\hline NMT & 0.688 & 0.109 & $0.008+$ & $0.016+$ & $0.016+$ & $0.008^{\dagger}$ \\
\hline BS & 0.812 & 0.195 & - & 0.078 & - & - \\
\hline$H T_{\text {augm 0mm }}$ & $0.031+$ & 0.063 & $0.016^{\dagger}$ & 0.250 & 0.250 & 0.250 \\
\hline $\mathrm{HT}_{\text {augm } 1 \mathrm{~mm}}$ & 0.375 & 0.383 & $0.016^{\dagger}$ & 0.750 & $0.031+$ & 0.063 \\
\hline$H T_{\text {augm } 2 \mathrm{~mm}}$ & 0.578 & 0.383 & $0.008^{\dagger}$ & 0.875 & $0.031 \dagger$ & $0.031+$ \\
\hline$H \mathbf{T}_{\text {augm 3mm }}$ & 0.375 & 0.461 & $0.016^{\dagger}$ & 0.578 & $0.016+$ & 0.063 \\
\hline$H T_{\text {mucosa } 0 \mathrm{~mm}}$ & 0.938 & 0.688 & $0.047 \dagger$ & 0.375 & $0.047 \dagger$ & $0.016^{\dagger}$ \\
\hline$H \mathrm{~T}_{\text {mucosa } 1 \mathrm{~mm}}$ & 0.844 & 0.813 & 0.688 & 0.656 & 0.219 & 0.848 \\
\hline$H T_{\text {total } 0 \mathrm{~mm}}$ & 0.156 & 0.219 & $0.016^{\dagger}$ & 1.000 & $0.016 \dagger$ & $0.016^{\dagger}$ \\
\hline $\mathrm{HT}_{\text {total } 1 \mathrm{~mm}}$ & 0.438 & 0.813 & $0.031^{\dagger}$ & 0.313 & $0.016 \dagger$ & 0.063 \\
\hline \multicolumn{7}{|c|}{ 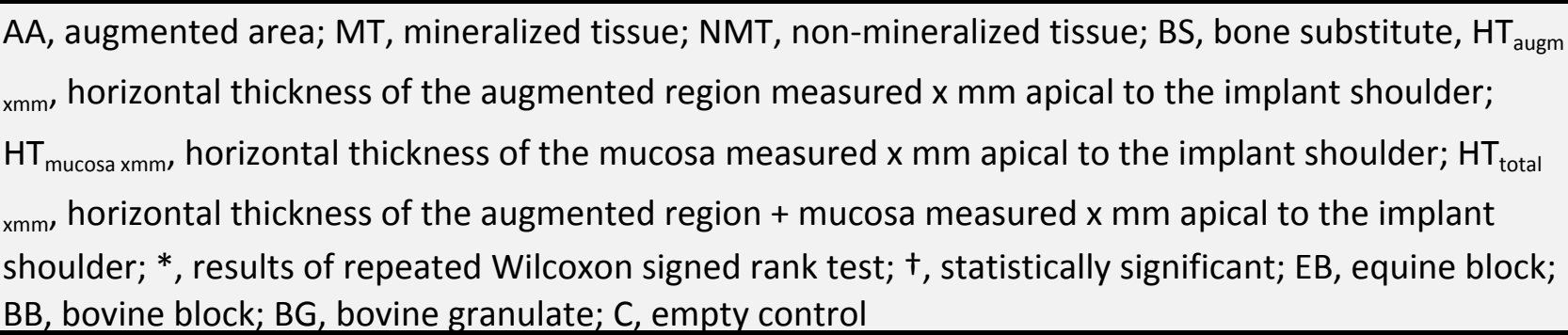 } \\
\hline
\end{tabular}




\begin{tabular}{|c|c|c|c|c|c|}
\hline \multirow[t]{2}{*}{ Parametar } & \multirow[t]{2}{*}{ Unit } & \multicolumn{4}{|l|}{ Treatment modality } \\
\hline & & $\begin{array}{l}\text { Equine block (EB) } \\
(n=8)\end{array}$ & $\begin{array}{l}\text { Bovine block (BB) } \\
(n=7)\end{array}$ & $\begin{array}{l}\text { Bovine granules (BG) } \\
(n=8)\end{array}$ & $\begin{array}{l}\text { Empty control (C) } \\
(n=8)\end{array}$ \\
\hline & & $\begin{array}{l}\text { Mean } \pm \text { SD } \\
(\mathrm{Q} 1, \text { median, } Q 3)\end{array}$ & & & \\
\hline AA & $\mathrm{mm} 2$ & $\begin{array}{l}19.9 \pm 5.3 \\
(16.4,21.2,24.3)\end{array}$ & $\begin{array}{l}19.5 \pm 3.0 \\
(18.2,20.6,21.6)\end{array}$ & $\begin{array}{l}17.8 \pm 5.6 \\
(12.2,18.4,22.9)\end{array}$ & $\begin{array}{l}11.9 \pm 2.3 \\
(9.9,11.8,12.8)\end{array}$ \\
\hline MT & $\mathrm{mm} 2$ & $\begin{array}{l}6.0 \pm 5.5 \\
(2.6,2.8,7.9)\end{array}$ & $\begin{array}{l}4.3 \pm 3.8 \\
(1.5,2.5,7.2)\end{array}$ & $\begin{array}{l}5.4 \pm 2.8 \\
(4.4,4.6,7.2)\end{array}$ & $\begin{array}{l}8.9 \pm 2.5 \\
(6.9,8.4,10.2)\end{array}$ \\
\hline NMT & $\mathrm{mm} 2$ & $\begin{array}{l}11.7 \pm 6.1 \\
(7.1,12.7,16.8)\end{array}$ & $\begin{array}{l}11.8 \pm 4.6 \\
(8.2,13.9,15.0)\end{array}$ & $\begin{array}{l}8.7 \pm 4.2 \\
(4.7,8.7,12.1)\end{array}$ & $\begin{array}{l}3.0 \pm 0.5 \\
(2.7,2.9,3.2)\end{array}$ \\
\hline BS & $\mathrm{mm} 2$ & $\begin{array}{l}2.1 \pm 1.6 \\
(1.0,1.7,3.8)\end{array}$ & $\begin{array}{l}3.5 \pm 1.1 \\
(3.0,3.9,4.4)\end{array}$ & $\begin{array}{l}3.7 \pm 1.5 \\
(2.6,3.8,4.8)\end{array}$ & - \\
\hline BS-MT surface $_{\text {sul }}$ & $\%$ & $\begin{array}{l}18.9 \pm 31.6 \\
(0.5,2.1,20.9)\end{array}$ & $\begin{array}{l}16.3 \pm 21.4 \\
(1.7,7.8,22.4)\end{array}$ & $\begin{array}{l}24.4 \pm 23.0 \\
(8.8,18.9,29.4)\end{array}$ & - \\
\hline
\end{tabular}

$\mathrm{AA}$, augmented area; MT, mineralized tissue; NMT, non-mineralized tissue; $\mathrm{BS}$, bone substitute, $\mathrm{BS}^{-\mathrm{MT}_{\text {surface }}, \text { surface }}$ fraction of bone substitute in contact with mineralized tissue; SD, standard deviation; Q1, first quartile; Q3, third quartile 


\begin{tabular}{|c|c|c|c|c|c|c|}
\hline \multirow[t]{2}{*}{ Parametar } & \multicolumn{6}{|c|}{ Statistical analysis* } \\
\hline & EB vs BB & EB vs BG & EB vs $\mathrm{C}$ & BB vs BG & BB vs C & BG vs C \\
\hline AA & 1.000 & 0.313 & $0.023^{\dagger}$ & 0.578 & $0.016+$ & 0.078 \\
\hline MT & 0.375 & 0.844 & 0.148 & 0.219 & $0.016 \dagger$ & $0.016^{\dagger}$ \\
\hline NMT & 0.813 & 0.250 & $0.008^{+}$ & $0.031+$ & $0.016+$ & $0.016^{\dagger}$ \\
\hline BS & $0.016+$ & $0.039+$ & - & 0.375 & - & - \\
\hline BS-MT $T_{\text {surface }}$ & 0.813 & 0.461 & - & $0.016+$ & - & - \\
\hline \multicolumn{7}{|c|}{ AA, augmented area; MT, mineralized tissue; NMT, non-mineralized tissue; BS, bone substitute, BS- } \\
\hline \multicolumn{7}{|c|}{$\mathrm{MT}_{\text {surface, }}$ surface fraction of bone substitute in contact with mineralized tissue; ${ }^{*}$, results of repeated } \\
\hline \multicolumn{7}{|c|}{$\begin{array}{l}\text { Wilcoxon signed rank test; }{ }^{\dagger} \text {, statistically significant; } E B \text {, equine block; BB, bovine block; BG, bovine } \\
\text { granulate; C, empty control }\end{array}$} \\
\hline
\end{tabular}



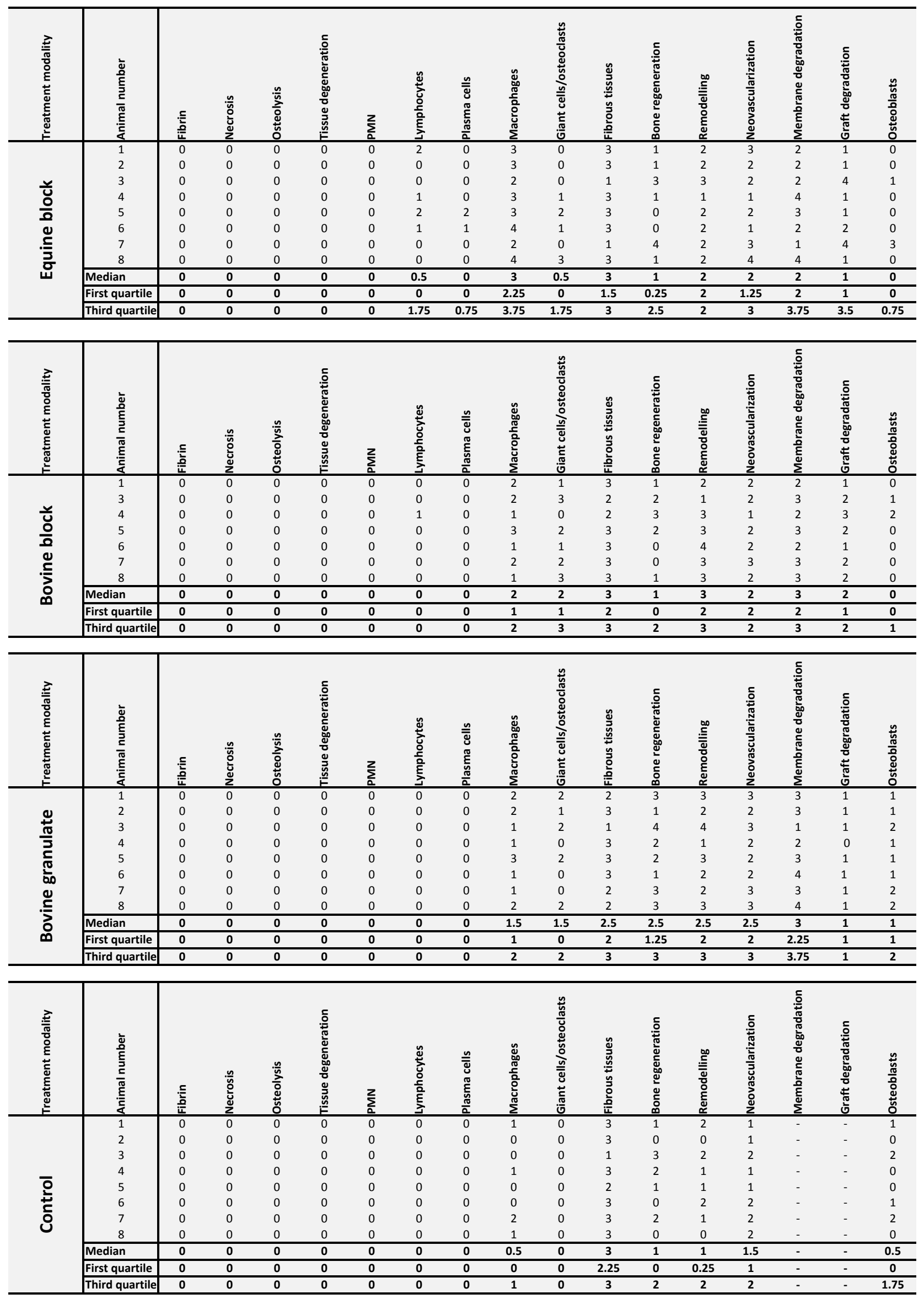


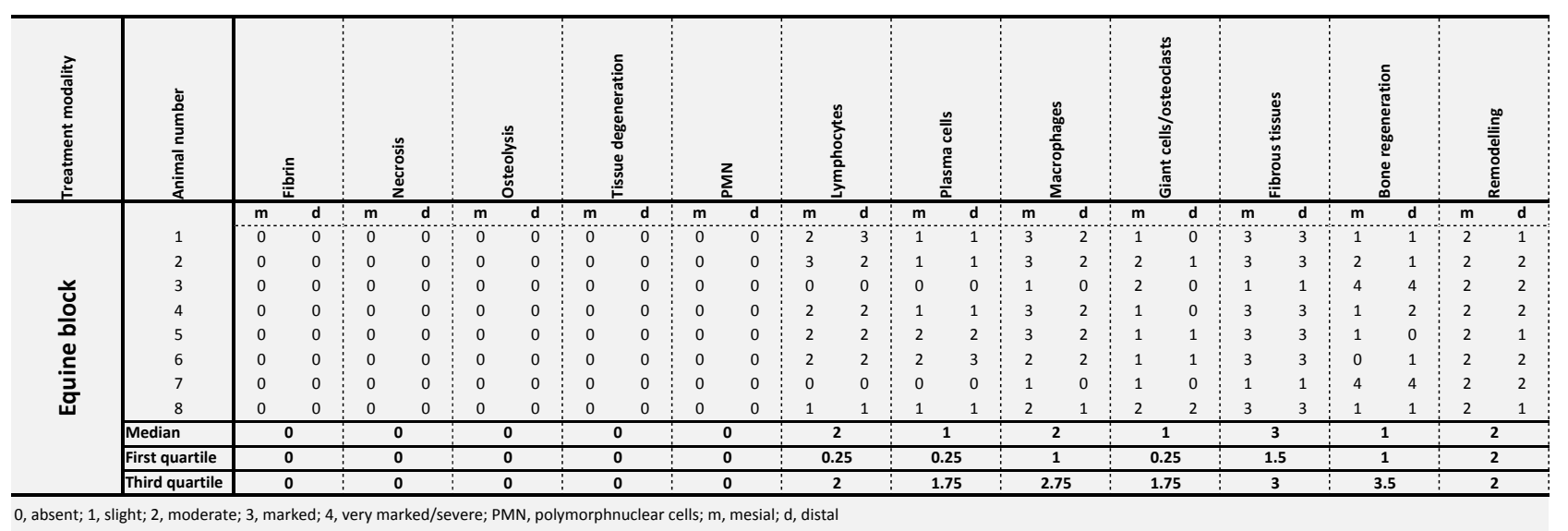

0 , absent; 1, slight; 2, moderate; 3, marked; 4, very marked/severe; PMN, polymorphnuclear cells; $m$, mesial; d, distal
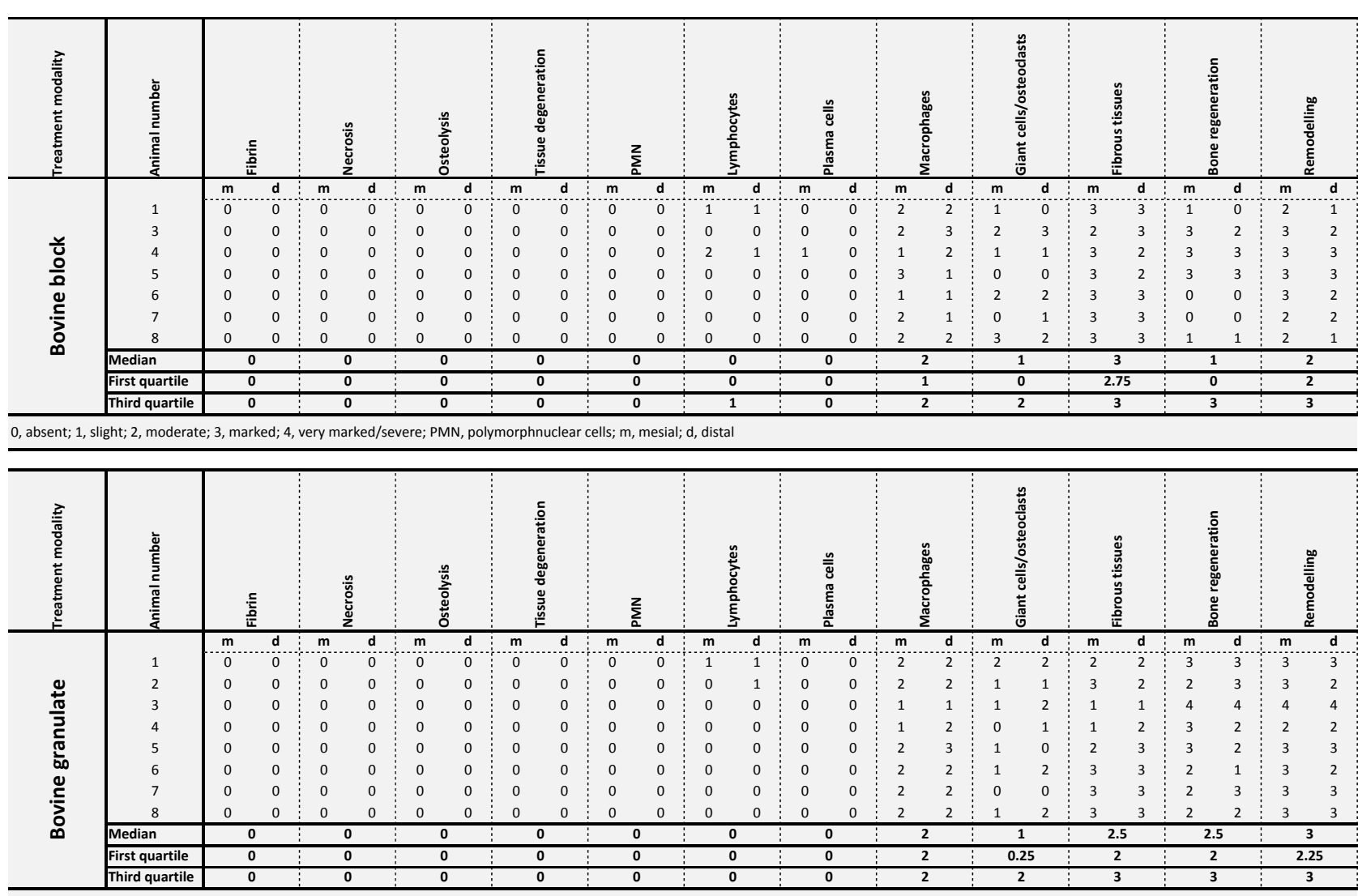

0 , absent; 1, slight; 2, moderate; 3, marked; 4, very marked/severe; PMN, polymorphnuclear cells; m, mesial; $d$, distal

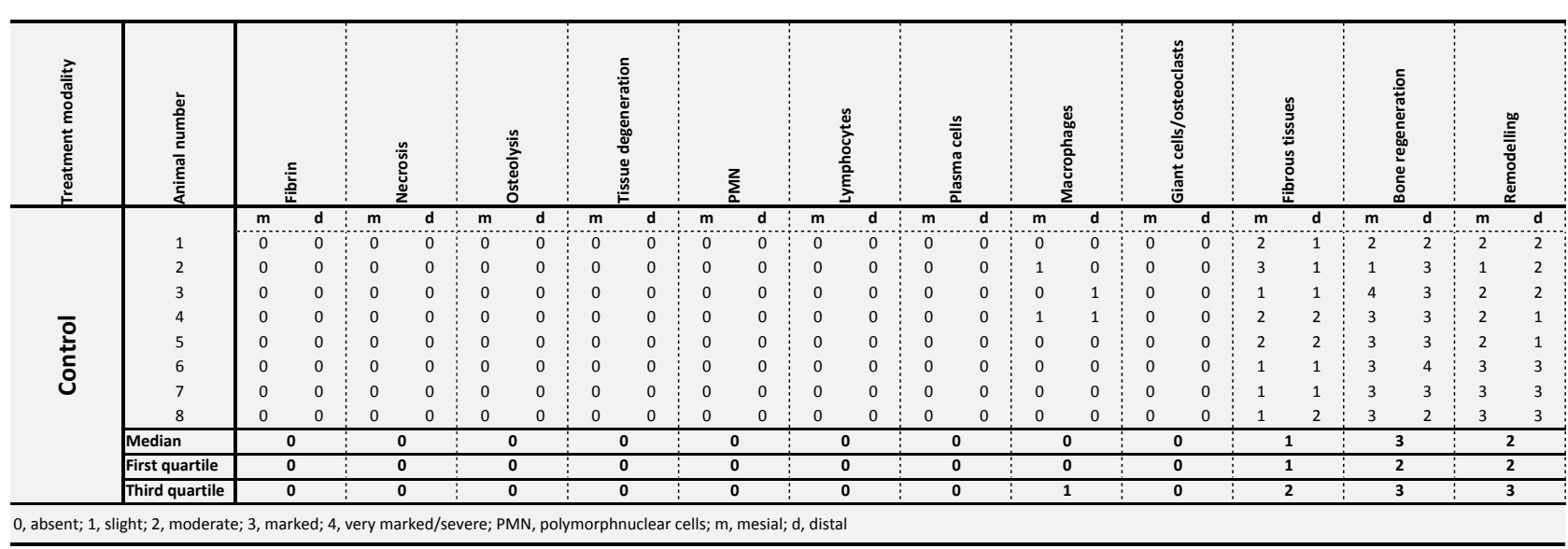




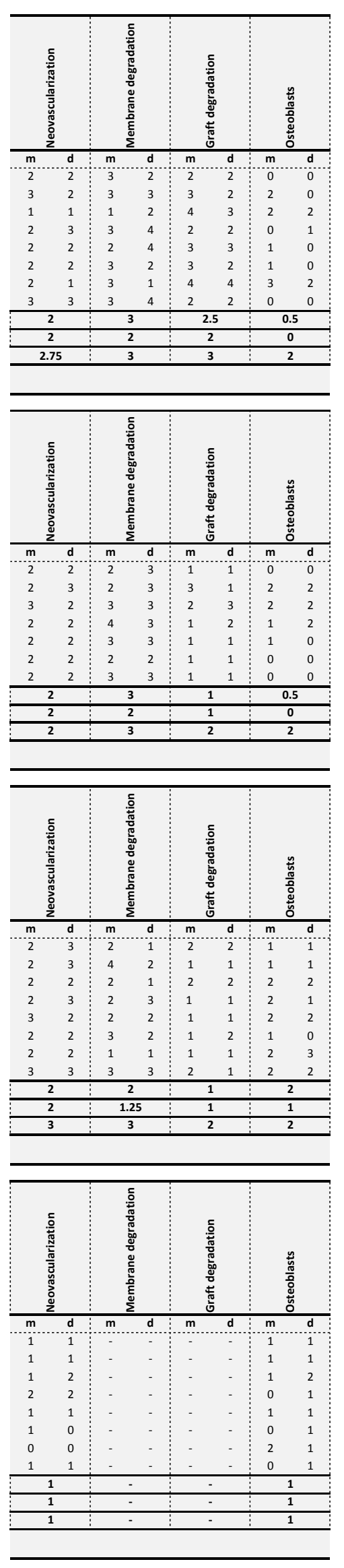

